\title{
A Proposal in Observation of Biosphere Day: Repairing The Biosphere through a Global Commons Trust Fund
}

$\mathrm{T}$ he Biosphere is in peril. World-wide, forests are being stripped, stressed, and burned. Lands that were once fertile are yielding to desert. The atmosphere and its stratospheric ozone shield are under assault. Wetlands and other natural breeding-grounds are vanishing. The oceans are being loaded with pollutants and swept bare of marine life. We are sullying the polar regions, perturbing the climate, and eradicating species.

All this and more is at last being acknowledged everywhere every day. There is no reason to repeat the alarm. What we need now are answers. Mine is a Global Commons Trust Fund (GCTF).

The 'Global Commons' are those sectors of the planet that remain above or beyond the territorial claims of any nation: the atmosphere, the high seas and their sea-beds, the regions of space such as are suited for satellites and space-stations, etc. Currently, because these areas are in effect 'unowned', they can be used and abused by anyone with relative impunity. One must say 'relative' because there are, thankfully, a growing number of international conventions that decry — and in some instances even seek to restrict - practices that degrade the 'commons' areas. Witness the agreements and declarations addressing oil pollution of the high seas, drift-netting, ocean dumping, and, more recently, the emissions of chlorofluorocarbons and other substances that damage the ozone shield.

\section{International Response neither Coherent nor Adequate}

But the present approach to the above threats is, overall, piecemeal and flimsy. Some emissions, such as soot, carbon compounds, and sewage, are utterly unregulated internationally, while others, such as $\mathrm{SO}_{2}$, are regulated by some countries, but not by others. And even where 'regulation' has been instituted, there is rarely any mechanism to call the violator to account with a financial charge of any sort. The familiar devices that we deploy against domestic polluters - civil judgments, fines, taxes, injunctions, etc. - are almost unknown in international application, particularly when the area impaired lies beyond any sovereign's jurisdictional limits, so that there is no nation with clear standing to complain.

If we were to rectify this practice, and charge even a fraction of the fair worth for the various uses to which nation-states put the Global Commons, we would advance two goals at once. The charges would curtail the level of abuse, and at the same time would underwrite the expenses of repairing the damage we have already done.

\section{Examples of Potential Revenues}

Let us consider some rough estimates of the potential revenue-base, if only to acquire some sense of the magnitude involved.

Start with the oceans. The world harvests 175,000 million pounds (c. 79,500 million $\mathrm{kg}^{*}$ ) of fish annually. A tax of only one-tenth of one per cent of the commercial value of all this fish would raise approximately $\$ 500$ millions annually for the Fund. The same token rate on offshore oil and gas would add perhaps $\$ 75$ millions.

There is another, dirtier use to which the world community puts the oceans: as a dump-site for wastes. The official figures, almost certainly under-reported, amount to 212 million metric tons of sewage sludge, industrial wastes, and dredged materials, yearly. A tax of only $\$ 1$ a ton would raise more than $\$ 200$ millions annually.

Nations use the atmosphere as they use the oceans - as a cost-free sewer for pollutants. By burning fossil fuels and living forests, Humankind thrusts some 7,000 million tons of carbon into the atmosphere annually. A carbon tax of only 10 cents a ton would raise $\$ 700$ million each year - ten times the current budget of the United Nations Environment Programme (UNEP). The same ten US cents a ton tax on sulphur dioxide and nitrous oxide would produce another $\$ 30$ millions.

The total reached thus far: over 1,000 million dollars annually. And that is before adding the yield of a tax on uneliminated chlorofluorocarbons and other ozone-depleting agents, on toxic incineration at sea, or on the blight of liquid refuse that runs from river to ocean. Consider also the uses of space, such as the rights to occupy prime orbital positions for geosynchronous satellites. Why should rights to these slots, the legacy and province of all Humankind, and worth hundreds of millions of dollars to users, be doled out free of charge, while those who would mend the planet are severely limited by a lack of financial resources?

\footnotetext{
* Professor Stone's figure referring solely to marine fishes, as confirmed by telephone, we should note that other living salt-water products are also pertinent and markedly swell the value of takings from the marine Commons, as indicated by the late Dr John A. Gulland in his chapter on 'Uses and Abuses of the Sea: Fishing' in Survival With The Biosphere (edited by Nicholas Polunin \& Sir John Burnett, Edinburgh University Press, 22 George Square, Edinburgh, Scotland, UK, 1992). - Ed.
} 


\section{Proposed User Charges Conservative}

Many people will object to the pollution-charge component of the above proposal, saying that it is outrageous to permit pollution-for-pay. The answer is that some pollution is inevitable, and it is more of an outrage that we let the polluters get away with it, as they currently do, free of charge.

Indeed, if there is a real objection to the GCTF, it is that the initial rates I have suggested are probably too paltry. Viewed as a strategy for reducing environmental damage, the levels advanced for discussion — ten cents a ton for carbon usage - are highly unlikely to confront the polluting nations with the full costs of the damage they are causing to the global environment, and therefore will fall short of inducing the 'right' amount of conservation and pollution control. Viewed from the reverse side - as a strategy for maximizing revenues for the environmental infrastructure - they fall short of extracting the full value of what users would pay if they were required to bid for restricted rights at an internationally-conducted auction. For example, to a nation seeking a site for waste disposal, the value of depositing wastes in the ocean or atmosphere is a mere fraction of the alternative costs it would face if forced to remove and dispose of them domestically. In the instances of some of the wastes that are now being deposited in the oceans, the costs of disposal on-shore are hundreds of dollars a ton. A case can be made that, at least as regards some wastes, it is safer to deposit them in the ocean than on land, where they pose greater hazards to health; not all ocean dumping need stop. What we should insist upon, however, is an end to the present practice, which allows the dumping free of charge, with no 'compensation' paid to the global community.

Funds raised even by modest charges for such uses of the Commons would finance international efforts that everyone agrees are necessary: to improve global monitoring and modelling; to prepare adaptive strategies, such as the development of fast-growing (and carbon-withdrawing) trees; to inaugurate and police improved methods of waste disposal; to gather and store genetic materials; to underwrite the transfer of environment-benign technology to developing nations; and to promote energy conservation and general antiwaste behaviour.

\section{Infrastructure Already Available}

The organizational infrastructure to do those jobs is already in place. It includes, along with UNEP and perhaps the newly-formed Global Environmental Facility, such organizations as the World Meteorological Organization (WMO), the World Wide Fund for Nature (WWF), the UN Food and Agriculture Organization (FAO), and, among the most important, the World Conservation Union (the new name of the former International Union for Conservation of Nature and Natural Resources [IUCN]), which serves as a sort of umbrella for hundreds of governmental and nongovernmental organizations operating in these fields. All are capable of doing first-rate work. What they need now is the financial wherewithal.

Some people will say this is 'too idealistic'. To be sure, not every nation will blithely submit: there will be resistance among the less-developed countries (LDCs). But these LDCs are by no means the worst polluters, and therefore do not face the highest levies; consequently their participation is not critical to the Fund's success.

Some countries will object to any tax on activities within their territories - or, particularly in the case of coastal states, within the recently asserted Exclusive Economic Zones (EEZs, which extend the coastal states' sovereign control, generally 200 nautical miles [370.4 km] seawards). But our response should be that the charges are not for what nations do within their boundaries - as traditionally defined or as extended via the EEZs. The levy is for the effects of their activities on the 'outside' world. Similarly, we grant that many of the activities proposed for taxation, such as fishing and petroleum extraction, will fall on coastal states for operations within 'their own' EEZs. But let us keep in mind that many non-coastal, landlocked nations along with many scholars - continue to regard the 'enclosure' of the oceans through EEZs as semilegitimate, at best. Allowing the coastal states to supply exclusive management across these zones makes a fair amount of sense - some management of ocean resources is better than none. But allowing the coastal states to snatch all the wealth without any accounting to the rest of the world, just because it happens to be closer to them, is indefensible. A sensible settlement would be to tax coastal states on the benefits which they have realized through their encroachments on what had been common heritage area, with the revenues paid into a fund for the Commons: the GCTF.

\section{The Present Proposal Distinguished from Predecessors}

It is true that superficially similar proposals have been advanced in the past, without making much political headway. But the GCTF can be distinguished at least from some other like-sounding plans distinguished in ways that may make the GCTF both more effective and more 'saleable' politically.

First, the GCTF can be differentiated from a host of plans - such as that put forward by the late Rajiv Gandhi, of India, to tax each developed nation a fraction of its Gross National Product and to distribute the funds to less-developed countries. While Gandhi called his proposal a Planet Protection Fund, the transparent intent was to redistribute wealth from rich countries to poor ones. The aim may be noble. But it ought not to 
be confused with the GCTF, which would link levies not to each nation's wealth per se but to its use of the Commons, and would restrict application of the revenue raised to the maintenance and repair of the Commons (or, at the widest, to other distinctly environmental projects). This leaves developmental financing in the province of the developmental banks and relief agencies, which should restrict their support to proposals that have received favourable independent environmental impact assessments (EIAs, see subsequent Guest Comment).

Second, many of the proposals that are now being voiced are limited to a single activity - most often, a tax on the use of carbon. By contrast, the idea of the GCTF is comprehensive: to bring all economic employment of the Commons under an overall plan, ranging from uses of the ocean to uses of the atmosphere and of space, and in foreseeable circumstances also of land.

Third, the GCTF has to be distinguished, as well, from proposals that each nation impose a special surtax on its own firms' use or output of environmentally-harmful agents. Such plans, unlike Gandhi's, are not mere taxes on wealth. They focus, in the manner of the proposed GCTF, on environmentally-injurious activities, and are well worth serious consideration. But these proposals typically leave the funds produced with the taxing nation for its own internal use, with uncertain implications. Depending upon each country's domestic politics and budgetary processes, there is no assurance that the taxes will curtail the abuses significantly. Each taxing nation may to some degree substitute emission taxes for corporate taxes. Worse, the taxing nation could come to rely on the pollution surtaxes as a new source of government resources, and thereby lose its ardour for eliminating the pollution- at the cost of eliminating the new resources-base. By contrast, the GCTF would remove the levies from national control and place them at the disposal of international agencies. As a consequence, under the GCTF, each nation, faced with the prospect of an outflow of funds if its agencies and firms do not perform suitably, is more likely to throw its full weight behind compliance.

Finally, there may be some political virtue in the very modesty of the GCTF proposal as outlined above. Increasingly, one hears proposals for levying truly towering taxes, particularly on carbon usage. For example, in 1990 Brazilian president-elect Fernando Collor proposed a UN-managed tax of $\$ 100$ a ton for $\mathrm{CO}_{2}$ emissions, reckoned (on Collor's basis for calculation) to generate $\$ 450,000$ millions annually.

Whereas a 10 cents-a-ton carbon tax impresses me as too low (except as a starter), taxes of $\$ 100$ a ton strike me, first, as diplomatically unachievable. EC nations are balking at far less. Indeed, considering the present uncertainties about the real hazards of climate change, it is unclear that the benefits of a levy on that scale (in terms of avoided future risk) warrant such a drastic dislocation of global economies as $\$ 100$ a ton would imply. Moreover, even if such a tax were realistic, one has to wonder: should the nations of the world, even those of us who admire the UN system, be prepared to place sums so vast $-\$ 450,000$ millions per year for carbon emissions alone - at the disposal of the organization, whether under a mandate to underwrite expanded operations or to distribute it nation-by-nation in a great political banquet? I doubt it.

\section{Conclusion}

The Global Commons Trust Fund is not merely a roundabout scheme to take wealth from the rich nations and redistribute it to the poor. It is different - and more generally acceptable to those nations whose support would be critical for its implementation. It simply seeks, from users of the Global Commons, a reasonable fee for their use of the Commons - so as to apply it back to the Commons, for the maintenance and repair of the Earth.

Should not such an idea be placed on the table at the UNCED Conference in Rio this June?

CHRISTOPHER D. STONE*
The Law Center
University of Southern California
699 Exposition Boulevard
University Park
Los Angeles
California $90089-0071$, USA.

* Christopher D. Stone is Roy P. Crocker Professor of Law at the University of Southern California, Los Angeles, California 90089-0071, USA. He serves as Environmental Conservation's Advisory Editor in Environmental Law. 